\title{
Upregulation of stem cell antigen-1 in the lung of neonatal mice exposed to environmental cigarette smoke
}

\author{
ALBERTO IZZOTTI $^{1}$, FRANCESCO D'AGOSTINI $^{1}$, PATRIZIA LARGHERO ${ }^{1}$, CRISTINA CARTIGLIA ${ }^{1}$, \\ GIORGIA TRAVAINI ${ }^{1}$, ROUMEN BALANSKY ${ }^{1,2}$, VERNON E. STEELE $^{3}$ and SILVIO DE FLORA ${ }^{1}$ \\ ${ }^{1}$ Department of Health Sciences, University of Genoa, I-16132 Genoa, Italy; ${ }^{2}$ National Center of Oncology, \\ 1756 Sofia, Bulgaria; ${ }^{3}$ National Cancer Institute, Rockville, MD, USA
}

Received March 30, 2009; Accepted April 30, 2009

DOI: $10.3892 /$ or_00000458

\begin{abstract}
Mice are particularly susceptible to carcinogens when exposure starts early in life. We evaluated the expression of stem cell antigen-1 (Sca-1) gene in the lung of variously aged CD-1 mice, either untreated or exposed to environmental cigarette smoke (ECS) and/or to a light source. Sca- 1 expression progressively decreased with age. The expression of Sca-l gene and the amount of $S c a-1$ protein, which was exclusively localized in endothelial cells of the pulmonary vasculature, were significantly upregulated in mice exposed either to ECS or ECS plus light throughout the weaning period, starting at birth. These findings may contribute to explain the high vulnerability of mouse lung early in life.
\end{abstract}

\section{Introduction}

There is adequate reason to suspect that perinatal exposures to carcinogens contribute to both childhood cancers and cancers appearing later in life (1), and certain adult diseases may have their origins early in life (2). In particular, early age smoking has been viewed as an independent risk factor for lung cancer, and adolescence may constitute a critical period during which tobacco carcinogens can induce fields of genetic alterations (3).

Several factors may contribute to the high susceptibility to carcinogens early in life. The sudden transition from the maternal-mediated respiration of the fetus to the autonomous pulmonary respiration of the newborn produces a tremendous oxidative stress that only recently was shown to produce extensive nucleotide alterations in the lung. In fact, we found a 5-fold increase of bulky DNA adduct levels and a 2-fold

Correspondence to: Dr Silvio De Flora, Department of Health Sciences, University of Genoa, Via A. Pastore 1, I-16132 Genoa, Italy E-mail: sdf@unige.it

Key words: stem cell antigen-1, environmental cigarette smoke, neonatal mice, lung carcinogenesis increase of oxidatively generated DNA damage during the few hours elapsing from the last day of fetal life to the newborn situation in mouse lung (4). In parallel, cDNA microarray analyses showed the upregulation of a number of genes $(4,5)$, which mainly tend to attenuate the birth-related oxidative stress and DNA damage. Moreover, oxidatively generated DNA damage in the respiratory tract (6) and in the cardiocirculatory system (7) was significantly higher in mice exposed to environmental cigarette smoke (ECS) since birth throughout the weaning period as compared with their dams exposed in the same cages. Other mechanisms that may account for the higher vulnerability to carcinogens soon after birth are the increased proliferation rate in neonatal organs and cells, also including proliferation of type-II alveolar cells (8), which results in alveolarization during the first 12 days of postnatal life (9). In addition, newborns may have alterations of xenobiotic metabolism, such as lower levels of glutathione $S$ transferases (10), and of certain DNA repair mechanisms, such as lower levels of DNA methyltransferases (11) and DNA polymerases (12). Recently, we demonstrated that mainstream cigarette smoke (MCS) is a potent carcinogen in mice when exposure starts at birth (13).

The objective of the present study was to evaluate whether a marker of stem cells and of differentiated cells thereof may be affected in the lung of mice exposed to ECS during different life stages. To this purpose, we evaluated stem-cell antigen-1 (Sca-1) gene expression and protein in the lung of the same mice used in previous studies $(6,7)$ including neonatal mice, post-weanling mice and their dams, either untreated or exposed to ECS and/or light. Moreover, we analyzed the lungs of mouse fetuses exposed transplacentally to ECS, whose liver had been used in a previous study (14). Sca-1, a marker of hematopoietic stem cells, is a phosphatidylinositol-anchored glycoprotein, which is identical in mouse bone marrow and peripheral lymphocytes (15). The Sca-1 protein is encoded by the $L y-6 A / E$ gene, a small 4-exon gene that is tightly controlled in its expression in hematopoietic stem cells (16).

We report here that the expression of $S c a-1$ tends to decrease with age in the postnatal life. Moreover, Sca- 1 gene and Sca-1 protein, which appears to be exclusively localized in endothelial cells of the pulmonary vasculature, are upregulated following exposure of neonatal mice to ECS throughout the weaning period. 


\section{Materials and methods}

Mice and experimental groups. Pregnant Swiss CD-1 albino mice were purchased from Harlan Italy (San Pietro al Natisone, Udine, Italy). The mice were housed individually in Makrolon cages on sawdust bedding and maintained on a standard rodent chow (Teklad 2018 Rodent, Harlan, Italy) and tap water ad libitum. The cages were kept in a cabinet where filtered air was circulated. The temperature of the animal room was $23 \pm 2^{\circ} \mathrm{C}$, with a relative humidity of $55 \%$ and a $12-\mathrm{h}$ day/night cycle. The housing and treatments of mice were in accordance with NIH, Italian, and institutional guidelines.

For the study in fetuses, we used the lungs of mice whose liver had been used in a previous study (14). Five pregnant mice had been kept in filtered air (sham-exposed), while 5 mice had been exposed to ECS throughout pregnancy. On the 18th day of pregnancy, 5 mice per group were anesthetized with diethyl ether and sacrificed by cervical dislocation. Lungs were collected from 4 fetuses per dam, thus accounting for a total of 10 fetus lungs per each one of the two experimental groups. The lungs were immersed in an RNA stabilizing buffer and stored at $-80^{\circ} \mathrm{C}$ until use for molecular analyses.

For the study in newborns, post-weanling mice and their dams, a total of 26 pregnant mice generated on an average 10 litters, for a total of 260 new generation mice. The neonatal mice belonging to one litter were sacrificed immediately after birth, and their lungs were collected and stored at $-80^{\circ} \mathrm{C}$. The remaining neonatal mice and their dams were divided into 4 experimental groups, including: i) sham-exposed mice, kept in filtered air, ii) ECS-exposed mice, iii) light-exposed mice, and iv) mice exposed to both ECS and light. All treatments started within the first $12 \mathrm{~h}$ of life, and each dam was kept in the same cage with its litter during treatments. When the infant mice became post-weanling, $\sim 5$ weeks after birth, they were distinguished by gender. All dams (5-7/ group) and sub-groups of 10 post-weanling mice (5 males and 5 females/group) were deeply anesthesized and sacrificed by cervical dislocation, while all remaining mice were kept alive for a long-term study (17). Body fluids and various organs were collected and used for evaluating a variety of intermediate biomarkers in the hematopoietic system and respiratory tract (6) and in the cardiovascular system (7). The upper lobe of the right lung was collected and used for RTqPCR and Western blot analyses, while the left lung was fixed in buffered formalin for immunohistochemical analyses.

Exposure to ECS and/or light. A whole-body exposure of mice to ECS was achieved by using a smoking machine (model TE-10c, Teague Enterprises, Davis, CA, USA), adjusted to produce a combination of SCS $(89 \%)$ and MCS (11\%). Five Kentucky reference cigarettes (Tobacco Research Institute, University of Kentucky, Lexington, KY) were burnt. In the study in transplacentally exposed fetuses we burnt 2R1 cigarettes without filter, having a declared content of $44.6 \mathrm{mg}$ tar and $2.5 \mathrm{mg}$ nicotine each, which accounted for an average total particulate matter (TMP) in the exposure chambers of $83.2 \mathrm{mg} / \mathrm{m}^{3}$. In the study in neonatal mice and their dams we burnt 2R4F filtered cigarettes, having a declared content of $9.2 \mathrm{mg}$ tar and $0.8 \mathrm{mg}$ each, which accounted for an average

TMP of $63.3 \mathrm{mg} / \mathrm{m}^{3}$. In both studies exposure was daily, $6 \mathrm{~h} /$ day divided into two rounds with a 3 -h interval.

Exposure of neonatal mice and their dams to an illumination system simulating sunlight was obtained by using halogen quartz bulbs, incorporated into dichroic spot lamps of $12 \mathrm{~V}$ and $50 \mathrm{~W}$ (Leuci, File, Lecco, Italy). The lamps were covered with filters cutting UV-C light (WG 280, Schott Optics Division, Mainz, Germany). The illuminance level was 10,000 lux, which was achieved by regulating the distance between the bulb and the back of mice at $\sim 50 \mathrm{~cm}$. The mice were exposed daily for $6 \mathrm{~h} /$ day.

A combined exposure of mice to ECS and light was achieved by applying the following schedule: $3 \mathrm{~h}$ ECS, $3 \mathrm{~h}$ light, $3 \mathrm{~h} \mathrm{ECS}$, and $3 \mathrm{~h}$ light. Light and ECS were not simultaneously used in order to avoid the risk of photoalterations of ECS components (18).

RNA extraction and gene expression. Analysis of the transcriptional activity of $S c a-1$ gene was performed by mRNA reverse transcription reaction followed by qPCR. In order to have sufficient amounts of RNA, the lung samples from fetuses, newborns, post-weanling mice, and their dams were pooled within each experimental group. RNA was extracted from $50 \mathrm{mg}$ tissue by using a commercially available kit (Purelink RNA Purification Kit, Invitrogen, Carlsbad, CA, USA). Unless otherwise specified, all reagents were from Invitrogen. PCR primers and qPCR molecular beacons were from TIB MolBiol (Genoa, Italy). qPCR primers and molecular beacons were designed using the Beacon Designer 6.0 software (Premier Biosoft International, Palo Alto, CA, USA). All qPCR steps were performed in a rotating PCR real-time thermocycler (Corbett Research, Mortlake, Australia). The reverse transcription reaction was performed by mixing RNA $(2 \mu \mathrm{g})$ with $1 \mu \mathrm{l}$ random primers $(300 \mathrm{ng} / \mu \mathrm{l}), 1 \mu \mathrm{l} 10 \mathrm{mM}$ dNTPs mix, and water up to $12 \mu 1$. After $5 \mathrm{~min}$ at $65^{\circ} \mathrm{C}$, the mixture was chilled in ice for $1 \mathrm{~min}$ and then $7 \mu \mathrm{l}$ of the following mix were added: $5 \mathrm{X}$ first strand buffer $(4 \mu 1), 0.1 \mathrm{M}$ DTT $(2 \mu 1)$, and RNAse OUT $(1 \mu 1)$. After $2 \mathrm{~min}$ at $42^{\circ} \mathrm{C}$, SuperScript II RT (200 U) was added and the samples were further incubated at $42^{\circ} \mathrm{C}$ for $50 \mathrm{~min}$. The reaction was stopped by heating at $70^{\circ} \mathrm{C}$ for $10 \mathrm{~min}$. qPCR reactions were performed for Sca-1 and for the housekeeping gene beta-2 microglobulin $(B 2 m)$. To this purpose, the $10 \%$ of the reverse transcription reaction mixture was added to a qPCR mix composed as follows: 10X PCR buffer $(5 \mu 1), 100 \mathrm{mM}$ dNTPs mix $(0.4 \mu 1), 50 \mathrm{mM} \mathrm{MgCl}_{2}(2 \mu \mathrm{l}), 10 \mu \mathrm{M}$ Primer Sense $(1 \mu \mathrm{l}), 10 \mu \mathrm{M}$ Primer Antisense $(1 \mu \mathrm{l}), 10 \mu \mathrm{M}$ FAM/ HEX Molecular Beacons $(2 \mu 1)$, Platinum Taq Polymerase $2.5 \mathrm{U}(0.5 \mu \mathrm{l})$, and water up to $50 \mu 1$. The primer and probe sequences are summarized below:

$m$-Sca-1 Sense Primer $m$-Sca-1 Anti-sense Primer m-Sca-1 Molecular Beacon

$m-B 2 m$ Sense Primer $m-B 2 m$ Anti-sense Primer $m-B 2 m$ Beacon Sequence
TCAGGAGGCAGCAGTTATTGTG TGGCAACAGGAAGTCTTCACG CGCGATCAATATTAGGAGGGCAGA TGGGTAAGCAAAGATCGCG

CTTCAGTCGTCAGCATGG TACTTGAATTTGAGGGGTTTTC CGCGATCCGGTCAGTGAGACAAGC ACCAGAAGATCGCG 


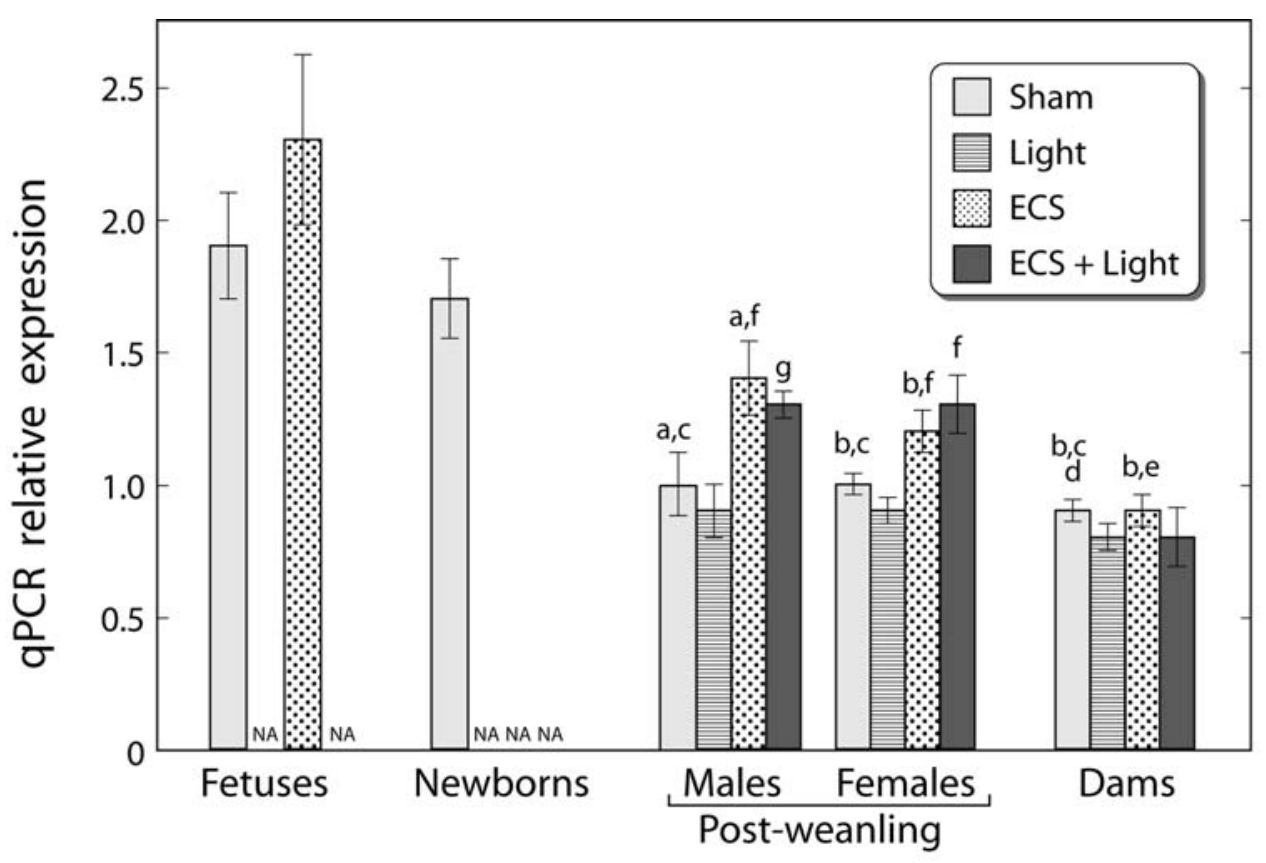

Figure 1. Differential expression of $S c a-1$ in the lung of CD-1 mice, as related to age and treatments. Gene expression was evaluated by qPCR in the lung of fetuses, newborns, post-weanling mice (males and females), and adult females (dams), either untreated (sham) or exposed for 35 days either to light, ECS, or ECS plus light. The results are expressed as qPCR relative expression normalized for $B 2 m$ and are means \pm SE of 4 - 14 independent analyses per experimental group. NA, not available. Statistical analysis: ${ }^{\mathrm{a}} \mathrm{P}<0.01$ and ${ }^{\mathrm{b}} \mathrm{P}<0.001$, as compared with fetuses; ${ }^{\mathrm{c}} \mathrm{P}<0.001$, as compared with newborns; ${ }^{\mathrm{d}} \mathrm{P}=0.07$ and ${ }^{\mathrm{e}} \mathrm{P}<0.01$, as compared with post-weanling females; ${ }^{\mathrm{f}} \mathrm{P}<0.05$ and ${ }^{\mathrm{g}} \mathrm{P}<0.01$, as compared with the corresponding sham.

The gene specific annealing temperature (aT) for each set of primers and probes were 56 and $51^{\circ} \mathrm{C}$ for $m-S c a-1$ and $m-B 2 m$, respectively. The reaction thermal cycles were $94^{\circ} \mathrm{C}$ for $15 \mathrm{~min}$, followed by 45 cycles at $94^{\circ} \mathrm{C}$ for $30 \mathrm{sec}$, the specific aT for $30 \mathrm{sec}$, and $72^{\circ} \mathrm{C}$ for $30 \mathrm{sec}$. The fluorescent signals were acquired at the end of the annealing cycle.

Depending on the amounts of available RNA, each pooled sample was tested in several replicate analyses, ranging between a minimum of 4 (fetuses) and a maximum of 12-14 (all other samples). The results, reported as qPCR relative expression normalized for $B 2 m$, are means $\pm \mathrm{SE}$ of the replicate analyses performed within each experimental group.

Immunohistochemistry. Sca-1 protein was evaluated by immunohistochemistry in 5- $\mu \mathrm{m}$ formalin-fixed and paraffinembedded lung sections from variously treated post-weanling mice and their dams. Sca-1/Ly6 goat monoclonal antibody (R\&D Systems, Minneapolis, MN, USA) was used for the detection of Sca-1 protein, at a working dilution of $5 \mu \mathrm{g} / \mathrm{ml}$. The sections were incubated for $1 \mathrm{~h}$ at room temperature. For chromogenic detection of labeling, an immunoperoxidase staining kit (Goat ABC Staining System, sc-2023, Santa Cruz Biotechnology) was used, following the manufacturer's instructions. The sections were counterstained with Mayer's hemalum and mounted in permanent medium with a glass coverslip.

Western blot analyses. Standardized amounts of lung homogenate protein $(40 \mu \mathrm{g})$, as evaluated by using the bicinchoninic acid method, were separated on $15 \%$ polyacrylamide-SDS gels and transferred to PVDF membranes. The Western blotting membrane was blocked in $5 \%$ powdered skim milk (Fluka, Buchs, Switzerland) in TTBS (25 mM Tris, $0.15 \mathrm{M}$ $\mathrm{NaCl}, 0.1 \%$ Tween-20, $\mathrm{pH} 7.5$ ), for $1 \mathrm{~h}$ at room temperature, and then incubated overnight at $4{ }^{\circ} \mathrm{C}$ with primary antibody (Sca-1 goat, R\&D Systems) in TTBS $(0.3 \mu \mathrm{g} / \mathrm{ml})$. The secondary donkey anti-goat antibody (IgG-HRP, Santa Cruz Biotechnology) was diluted 1:5,000 in TTBS and incubated for $90 \mathrm{~min}$ at room temperature. The immunoreaction was detected by ECL-plus system (Amersham Biosciences, Little Chalfont, UK). A rabbit polyclonal IgG (Santa Cruz Biotechnology) was used for the detection of the housekeeping protein glyceraldehyde-phosphate dehydrogenase (GAPDH). Densitometric analyses were performed by using the Image $\mathbf{J}$ 7.8 software (NCI, Bethesda, MD, USA), and the results were expressed as fold variations between the experimental groups.

Statistical analyses. The statistical significance of differences in gene expression, as related to age and/or treatment of mice, was evaluated by Student's t-test for unpaired data.

\section{Results}

Age-related decrease of Sca-1 expression in mouse lung. The results of the experiments evaluating $S c a-1$ expression in mouse lung, by using mRNA reverse transcription followed by qPCR, are summarized in Fig. 1. The baseline expression, detected in sham-exposed mice (light grey columns), was similar in fetuses and newborns and tended to decrease with age. In fact, $S c a-1$ expression was significantly lower in postweanling mice, both males and females, as compared with either fetuses or newborns. It was further lower in dams, with a difference that was borderline to statistical significance as compared with post-weanling females.

Upregulation of Sca-1 expression and Sca-1 protein following exposure of neonatal mice to ECS during the weaning period. 


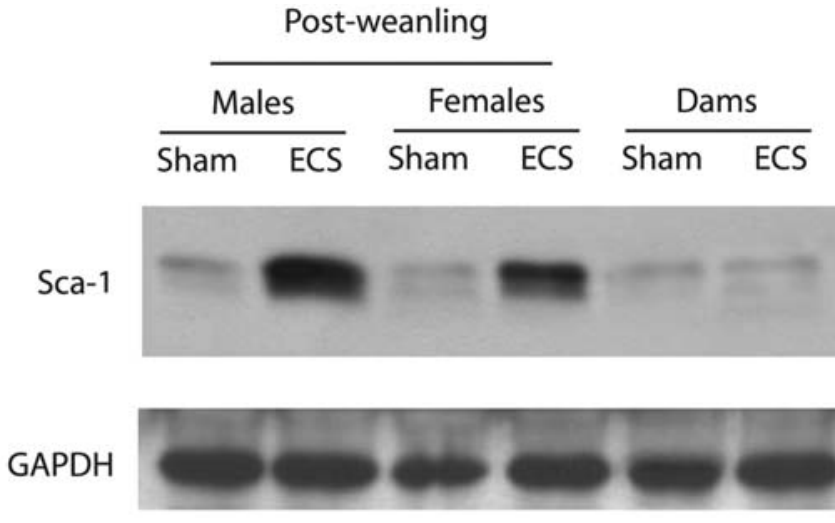

Figure 2. Western blot analyses showing the levels of Sca-1 protein and of the housekeeping protein GAPDH in the lung of variously aged mice, either sham-exposed or ECS-exposed.

As shown in Fig. 1, exposure of neonatal mice to light, from birth to weaning, or of dams, for an equivalent period of time (35 days), did not affect the baseline $S c a-1$ expression. In contrast, exposure of neonatal mice to either ECS or ECS plus light, from birth to weaning, significantly upregulated Sca-1 expression in both males $(+46.3 \%)$ and females $(+25.5 \%)$. Exposure of dams to either ECS and/or light did not affect $S c a-1$ expression. Exposure of pregnant mice to ECS throughout the gestation period resulted in an appreciable increase of $S c a-1$ expression in fetus lung $(+21.1 \%)$, but the difference with sham-exposed mice did not reach the statistical significance threshold.

Western blot analyses of lung samples from post-weanling mice and their dams confirmed that there is upregulation of Sca-1 protein in the lung of neonatal mice of both genders exposed to ECS during the weaning period (Fig. 2). Densitometric analyses, taking into account the results obtained with the housekeeping gene GAPDH, indicated that the ECS/Sham ratio for Sca-1 protein was 1.0 in dams, 1.7 in post-weanling females, and 2.0 in post-weanling males.

Selective localization of Sca-1 protein in the pulmonary vasculature. Due to its semi-quantitative nature, the immunohistochemical analysis of Sca-1 protein in the lung of postweanling mice and their dams could not discriminate the amounts of protein as related either to age or to exposure to
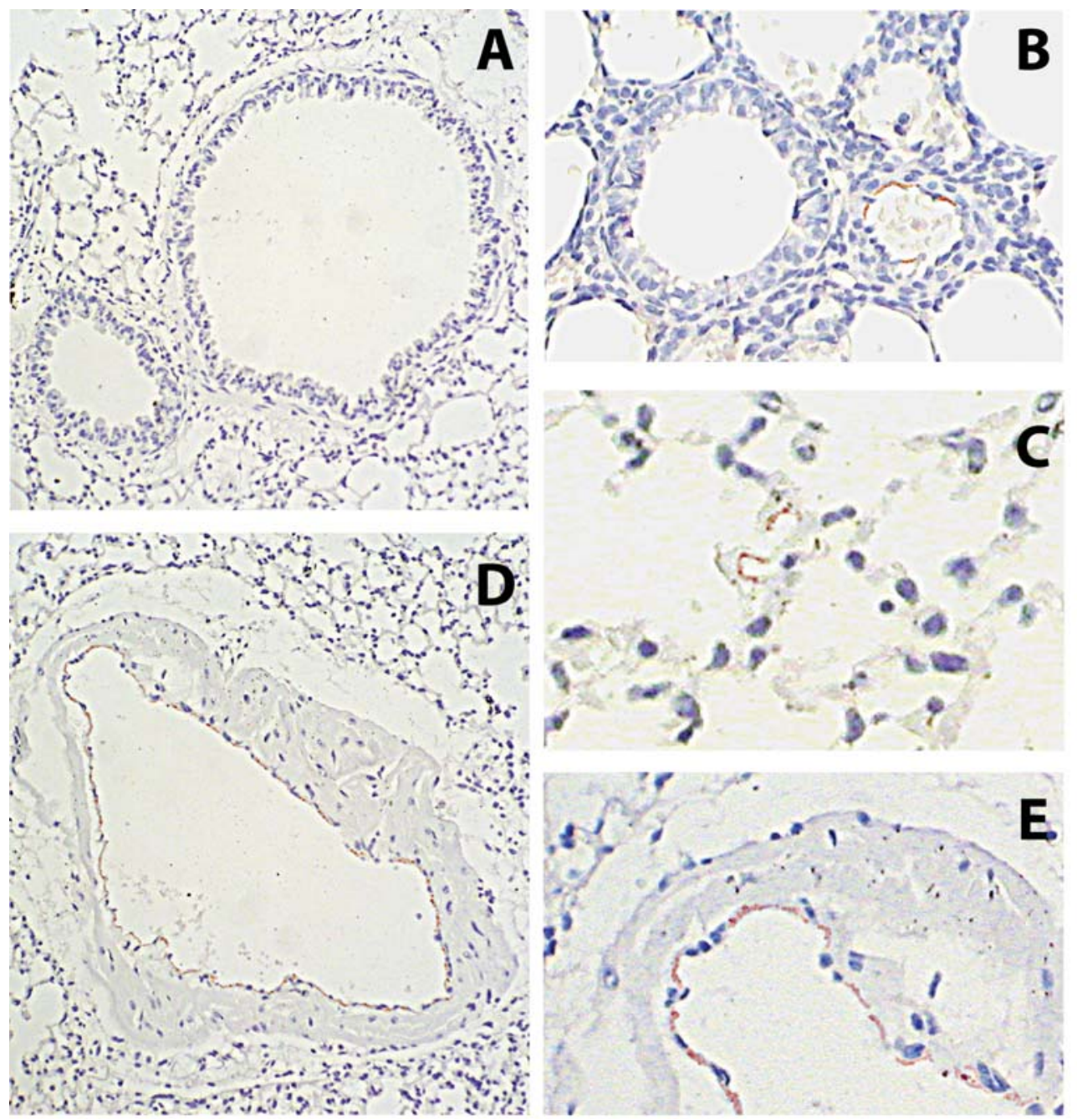

Figure 3. Selective localization of Sca-1 protein in the pulmonary endothelial vasculature. Sca-1 was analyzed by immunohistochemistry in paraffin sections of lung from post-weanling mice. Sca-1 was not detectable by immunoperoxidase staining in bronchial, bronchiolar, and alveolar epithelial cells (A and B), whereas it was well evident, in the form of brownish staining, in virtually all endothelial cells of large and small vessels (B-E). Original magnification, $\mathrm{x} 100$ (A and D) and X400 (B, C and E). 
ECS. However, this kind of analysis was useful to localize Sca-1 in lung cells (Fig. 3). No Sca-1 protein was detectable in any cell of the bronchial, bronchiolar, or alveolar epithelia (Fig. 3A-C). Conversely, Sca-1 protein, in the form of brownish staining, was consistently detectable in endothelial cells of the pulmonary vasculature, both capillaries (Fig. 3C) and larger vessels (Fig. 3D and E).

\section{Discussion}

The results of the present study provide evidence that the baseline $S c a-1$ expression in mouse lung tends to decrease with age in the postnatal life. The observed age-related loss of Sca-1 expression is in agreement with the finding that, in healthy humans aged 1-81 years, there was an inverse relationship between age and levels of circulating endothelial progenitor cells, a hematopoietic stem cell subtype (19).

Of particular interest was the finding that $S \mathrm{ca}-1$ was overexpressed following exposure to ECS, but only when exposure started at birth. As assessed by evaluating Hoechst 33342 efflux, a typical property of stem cells, non-hematopoietic side population cells of mouse lung were found to express Sca-1 (20). Moreover, primary cultures of neonatal pulmonary cells express $\mathrm{Sca}-1$ and other stem cell markers, among which Clara cell secretion protein, suggesting that these cells represent a subpopulation of Clara cells implicated as lung stem/progenitor cells in lung injury models (21). Clara cells are believed to play a role not only in carcinogenesis but also in the pathogenesis of smoke-related chronic obstructive pulmonary diseases (22).

However, $S c a-1$ is a typical marker of bone marrowderived hematopoietic stem cells, and its expression in nonhematopoietic organs, including the adult mouse lung, has been ascribed to the localization of the encoded glycoprotein on the surface of endothelial cells throughout the pulmonary vasculature, thereby marking cells of bone marrow origin (23). This hypothesis was supported by our immunohistochemical analyses, showing that Sca-1 protein was localized in virtually all endothelial cells of the pulmonary vasculature, whereas it was not detectable in either bronchial, bronchiolar or alveolar cells. It has been proposed that repetitive wounding and bone marrow-derived stem cell mediated repair may play a role in lung cancer development and dissemination (24). Similarly, using a model of Helicobacter pylori infection in mice, up to $90 \%$ of gastric mucosa cells were replaced by bone marrow-derived cells, thus suggesting that epithelial cancers may originate from marrow-derived sources (25). It is likely that, in our study, the chronic inflammatory process induced by ECS in the highly replicating mouse neonatal lung cells may have recruited bone marrow stem cells as a repair mechanism.

Therefore, the observed variations of $S c a-1$ in mouse lung, as related to exposure of neonatal mice to ECS, are very likely to reflect the amounts of bone marrow-derived cells in the pulmonary vascular endothelium. This conclusion is consistent with our previous findings that exposure to ECS upregulates vascular endothelial growth factors (VEGFs), endothelin, and other angiogenesis-related genes or proteins in rodent tissues, including the fetus liver of transplacentally exposed Swiss mice (14), the lung of A/J mice, both wild- type and P53 mutant (26), and the lung of Sprague-Dawley rats (27). Moreover, exposure of mice to either MCS or ECS induced blood vessel proliferation in the lung as well as in liver and kidney $(13,17)$. Sca-1-positive cells and their derived cells demonstrated significant recruitment to Lewis lung carcinoma in a syngenic bone marrow transplantation mouse model, although these cells were not found to functionally contribute to tumor neovascularization (28). Moreover, Lewis lung carcinoma-derived tumor endothelium expresses significantly greater levels of Sca-1 protein than normal murine endothelium (29).

Together with other possible mechanisms, which have been described in the Introduction, the greater abundance of endothelial cells differentiated from bone marrow stem cells in the lung at birth and early in life, along with their further increase following exposure of mice to cigarette smoke, may contribute to explain the high vulnerability of neonatal mice to carcinogenesis of MCS (13) and to molecular, biochemical, cytogenetical, and early histopathological alterations induced by ECS in the respiratory tract (6) and in the cardiovascular system (7). It is likely that, in our study, the chronic inflammatory process induced by ECS in the highly replicating mouse neonatal lung cells may have recruited bone marrow stem cells as a repair mechanism. It is noteworthy that cultured stem-derived cells are more susceptible than more differentiated cells to chemically induced molecular alterations (30). These concepts are in agreement with the 'Barker hypothesis' (31) that early exposure to toxic agents could affect diseases later in life by their ability to alter stem cell pools in various tissues.

In conclusion, $S c a-1$ tends to decrease with age after birth in mouse lung. Sca-1 is exclusively localized in the pulmonary vasculature. Sca- 1 expression and Sca-1 protein in the lung are significantly increased when neonatal mice are exposed to ECS during the weaning period, which may contribute to explain the high susceptibility to smoke carcinogens early in life.

\section{Acknowledgements}

This study was supported by the U.S. National Cancer Institute (contract N01-CN53301) and Bulgarian Ministry of Education and Science.

\section{References}

1. Anderson LM: Introduction and overview. Perinatal carcinogenesis: growing a node for epidemiology, risk management, and animal studies. Toxicol Appl Pharmacol 199: 85-90, 2004.

2. Agrawal AK and Shapiro BH: Neonatal phenobarbital imprints overexpression of cytochromes $\mathrm{P} 450$ with associated increase in tumorigenesis and reduced life span. FASEB J 19: 470-472, 2005.

3. Wiencke JK and Kelsey KT: Teen smoking, field cancerization, and a 'critical period' hypothesis for lung cancer susceptibility. Environ Health Perspect 110: 555-558, 2002.

4. Izzotti A, Balansky R, Camoirano A, Cartiglia C, Longobardi M, Tampa E and De Flora S: Birth related genomic and transcriptional changes in mouse lung. Modulation by transplacental $\mathrm{N}$-acetylcysteine. Mutat Res Rev 544: 441-449, 2003.

5. Bonner AE, Lemon WJ, Devereux TR, Lubet RA and You M: Molecular profiling of mouse lung tumors: association with tumor progression, lung development, and human lung adenocarcinomas. Oncogene 23: 1166-1176, 2004. 
6. De Flora S, D'Agostini F, Balansky R, Camoirano A, Cartiglia C, Longobardi M, Travaini G, Steele VE, Pesce C and Izzotti A: High susceptibility of neonatal mice to molecular, biochemical and cytogenetical alterations induced by environmental cigarette smoke and light. Mutat Res Rev 659: 137-146, 2008.

7. Izzotti A, D'Agostini F, Balansky R, Degan P, Pennisi TM, Steele VE and De Flora S: Exposure of mice to cigarette smoke and/or light causes DNA alterations in heart and aorta. Mutat Res 644: 38-42, 2008

8. Yee M, Vitiello PE, Roper JM, Staversky RJ, Wright TW, McGrath-Morrow SA, Maniscalco WM, Finkelstein JN and O'Reilly MA: Type II epithelial cells are critical target for hyperoxia-mediated impairment of postnatal lung development. Am J Physiol Lung Cell Mol Physiol 291: L1101-L1111, 2006.

9. Foster JJ, Goss KL, George CL, Bangsund PJ and Snyder JM: Galectin-1 in secondary alveolar septae of neonatal mouse lung. Am J Physiol Lung Cell Mol Physiol 291: L1142-L1149, 2006.

10. Shupe T and Sell S: Low hepatic glutathione S-transferase and increased hepatic DNA adduction contribute to increased tumorigenicity of aflatoxin B1 in newborn and partially hepatectomized mice. Toxicol Lett 48: 1-9, 2004.

11. Coccia P, Salmona M, Diomede L, Citti L, Mariani L and Romano M: Liver DNA alkylation after a single carcinogenic dose of dimethylnitrosamine to newborn and adult CFW Swiss mice. Chem Biol Interact 68: 259-271, 1988.

12. Hanaoka F, Sayato J, Arai H, Hasegawa N, Inui N, Mitsui Y and Yamada M: Changes in DNA polymerases alpha, beta and gamma in mouse liver as a function of age. Mech Ageing Dev 23: 315-327, 1983

13. Balansky R, Ganchev G, Iltcheva M, Steele VE, D'Agostini F and De Flora S: Potent carcinogenicity of cigarette smoke in mice exposed early in life. Carcinogenesis 28: 2236-2243, 2007.

14. Izzotti A, Balansky R, Cartiglia C, Camoirano A, Longobardi M and De Flora S: Genomic and transcriptional alterations in mouse fetus liver after transplacental exposure to cigarette smoke. FASEB J 17: 1127-1129, 2003.

15. Van de Rijn M, Heimfeld S, Spangrude GJ and Weissman IL: Mouse hematopoietic stem-cell antigen Sca-1 is a member of the Ly-6 antigen family. Proc Natl Acad Sci USA 86: 4634-4638, 1989.

16. Ma X, Robin C, Ottersbach K and Dzierzak E: The Ly-6A (Sca-1) GFP transgene is expressed in all adult mouse hematopoietic stem cells. Stem Cells 20: 514-521, 2002.

17. D'Agostini F, Balansky R, Steele VE, Ganchev G, Pesce C and De Flora S: Preneoplastic and neoplastic lesions in the lung, liver, and urinary tract of mice exposed to environmental cigarette smoke and UV light since birth. Int J Cancer 123: 2497-2502, 2008.

18. De Flora S, Camoirano A, Izzotti A, D'Agostini F and Bennicelli C: Photoactivation of mutageno. Carcinogenesis 10: 1089-1097, 1989.
19. Jie KE, Goossens MH, van Oostrom O, Lilien MR and Verhaar MC: Circulating endothelial progenitor cell levels are higher during childhood than in adult life. Atherosclerosis 202: 345-347, 2008

20. Giangreco A, Shen H, Reynolds SD and Stripp BR: Molecular phenotype of airway side population cells. Am J Physiol Lung Cell Mol Physiol 286: L624-L630, 2004.

21. Ling TY, Kuo MD, Li CL, Yu AL, Huang YH, Wu TJ, Lin YC, Chen SH and $\mathrm{Yu}$ J: Identification of pulmonary Oct-4 ${ }^{+}$ stem/progenitor cells and demonstration of their susceptibility to SARS coronavirus (SARS-CoV) infection in vitro. Proc Natl Acad Sci USA 103: 9530-9535, 2006.

22. Braido F, Riccio AM, Guerra L, Gamalero C, Zolezzi A, Tarantini F, De Giovanni B, Folli C, Descalzi D and Canonica GW: Clara cell 16 protein in COPD sputum: a marker of small airways damage? Respir Med 101: 2119-2124, 2007.

23. Kotton DN, Summer RS, Sun X, Ma BY and Fine A: Stem cell antigen-1 expression in the pulmonary vascular endothelium. Am J Physiol Lung Cell Mol Physiol 284: L990-L996, 2003.

24. Haura EB: Is repetitive wounding and bone marrow-derived stem cell mediated-repair an etiology of lung cancer development and dissemination? Med Hypotheses 67: 951-956, 2006.

25. Houghton J, Stoicov C, Nomura S, Rogers AB, Carlson J, Li H, Cai X, Fox JG, Goldenring JR and Wang TC: Gastric cancer originating from bone marrow-derived cells. Science 306: 1568-1571, 2004.

26. Izzotti A, Cartiglia C, Longobardi M, Bagnasco M, Merello A, You M, Lubet RA and De Flora S: Gene expression in the lung of p53 mutant mice exposed to cigarette smoke. Cancer Res 64: 8566-8572, 2004

27. Izzotti A, Bagnasco M, Cartiglia C, Longobardi M, Balansky RM, Merello A, Lubet RA and De Flora S: Chemoprevention of genome, transcriptome, and proteome alterations induced by cigarette smoke in rat lung. Eur J Cancer 41: 1864-1874, 2005.

28. Shinde Patil VR, Friedrich EB, Wolley AE, Gerszten RE, Allport JR and Weissleder R: Bone marrow-derived lin(-)ckit(+)Sca-1+ stem cells do not contribute to vasculogenesis in Lewis lung carcinoma. Neoplasia 7: 234-240, 2005.

29. Allport JR and Weissleder R: Murine Lewis lung carcinomaderived endothelium expresses markers of endothelial activation and requires tumor-specific extracellular matrix in vitro. Neoplasia 5: 205-217, 2003.

30. De Flora S, Scarfî S, Izzotti A, D'Agostini F, Chang C-C, Bagnasco M, De Flora A and Trosko JE: Induction by 7,12dimethylbenz $(a)$ anthracene of molecular and biochemical alterations in transformed human mammary epithelial stem cells, and protection by N-acetylcysteine. Int J Oncol 29: 521-529, 2006.

31. Barker DJP: Maternal nutrition, fetal nutrition, and diseases in later life. Nutrition 13: 807-813, 1997. 